\title{
Condition of phase angle for a new VDGA-based multiphase variable phase shift oscillator from $0^{\circ}$ To $90^{\circ}$
}

\author{
Kasim K. Abdalla \\ Departement of Electrical Engineering, College of Engineering, University of Babylon, Iraq
}

\begin{tabular}{l} 
Article Info \\
\hline Article history: \\
Received Jul 20, 2019 \\
Revised Dec 19, 2019 \\
Accepted Feb 1, 2020 \\
\hline
\end{tabular}

Keywords:

Analog circuit

Analog signal processing

Multiphase sinusoidal oscillator

Variable phase angle oscillator

Voltage differencing gain

amplifier (VDGA)

Voltage-mode oscillator

\begin{abstract}
A novel interesting type of variable phase angle voltage mode oscillator using modern building block has been presented in this paper. The new proposed oscillator configuration which uses four voltage differencing gain amplifier (VDGA) and two grounded capacitors can generate two sinusoidal signals that change out of phase by 0 to 90 degree. It has four floating and explicit voltage mode outputs where every two outputs have the same phase. The circuit is characterized by (i) the condition of phase angle of the oscillation (PO) (this concept is introduced for the first time in this paper) can be tuned electronically (ii) the gain of the floating outputs can be controlled independently (iii) it provides electronic control of condition of oscillation (CO) and independent control of frequency of oscillation (FO). The Total Harmonic Distortion (THD) of the output waveforms was obtained and the results were reasonability values (less than $4.5 \%$ ). The non-ideal analysis and simulation results are investigated and confirmed the theoretical analysis based upon VDGAs implementable in $0.35 \mu \mathrm{m}$ CMOS technology. Simulation results include time response and frequency response outputs generated by using the PSPICE program.
\end{abstract}

Copyright $(2020$ Institute of Advanced Engineering and Science. All rights reserved.

\section{Corresponding Author:}

Kasim K. Abdalla,

Departement of Electrical Engineering,

College of Engineering, University of Babylon,

Najaf Road, Hilla, Babylon, Iraq.

Email: kasimkaa.11@gmail.com

\section{INTRODUCTION}

One of the most applications in analog signal processing is the sinusoidal oscillators, which have a linear circuit characteristic. Multiphase sinusoidal oscillators are common circuits in analog circuit design. Multiphase sinusoidal oscillators find applications in signal processing, instrumentation, measurement, communication and control systems [1-7]. Depending on the phase shift between the phases, the multiphase oscillator circuits are available in different angles [8-23]. All these generators are specified with fixed phase shift angles like the phase shifter. There are many circuits achieve variable phase shift by varying passive components or varactor diode, etc. But the variable phase shift angle sinusoidal oscillators by using modern building blocks is not finding in the open literature yet.

In the synthesis of analog signal processing configurations, there are many important electronic active elements (modern building blocks) which they are reviewed in [24, 25]. Modern building blocks found many applications in filtering, oscillating and immitance function circuits, such as Operational Transconductance Amplifiers (OTA) [26], operational amplifier [27], feed-back operational amplifiers (CFOAs) [28], Voltage differencing gain amplifier (VDGA) [29], Current Conveyors (CC) [30-33], etc. that have been frequently witnessed in literature. Recently, one of the significant electronically tunable active devices named voltage differencing gain amplifier (VDGA) is successfully used in analog signal processing circuits and analog wave generation [34]. It is the modified version of the VDTA and VDBA devices. VDGA is an attractive device due to its capability of adjusting the output voltage gain. 
There are various applications of variable phase shift sinusoidal oscillators such as quadrature amplitude modulators (QAM), phase modulators (PM), phase shift keying (PSK) etc., hunce the challenge of designing such circuit is an important characteristic to reduce the coplexty of the design by introducing one circuit with variable phase shift agenest multiple circuits produces multiple phase shift, therefore the main aim of this paper is to introduce a novel circuit that achieves a variable phase angle oscillator by using electronic active elements.

The proposed sinusoidal oscillator circuit introduced in this paper can generate two sinusoidal signals which change out of phase by 0 to 90 degree. The circuit uses four VDGAs and two grounded capacitors which preferred in monolithic fabrication. It has four floating outputs where every two outputs have the same phase angle that specified with explicit voltage mode. The circuit is characterized by (i) the condition of the phase shift angle of oscillation between the phases can be tuned electronically (ii) the gain of the floating outputs can be controlled independently (iii) it provides electronic control of the condition of oscillation (CO) and independent control of the frequency of oscillation (FO).

\section{PROPOSED CIRCUITS}

The active element voltage differencing gain amplifier (VDGA) was introduced in [35]. It is a fourterminal analog building block shown symbolically in Figure 1, where includes three high impedance terminals ( $\mathrm{p}, \mathrm{n}$ and $\mathrm{z}$ ) and one low impedance terminal $(\mathrm{w})$, in which its voltage at the terminal $\mathrm{z}$ is transferred to a voltage at the terminal $w$ amplified by adjustable transfer gain $(\boldsymbol{\beta})$.

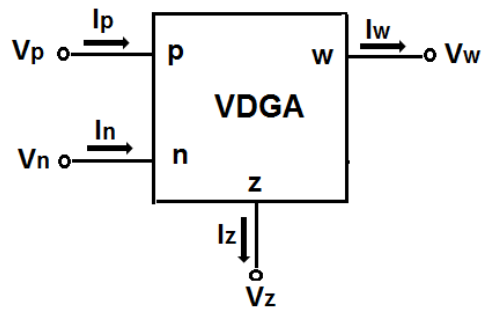

Figure 1. Circuit symbol of VDGA

The ideal terminal characteristics of VDGA can be defined by the following set of equations:

$$
I_{p}=I_{n}=0, I_{z}=g_{m}\left(V_{P}-V_{N}\right) \text { and } V_{w}=\beta V_{z}
$$

where $g_{m}$ is the transconductance, $V_{\mathrm{p}}$ and $V_{\mathrm{n}}$ are the input voltages at non-inverting and inverting input terminals, respectively, and $\beta$ is the voltage gain. As defined in the literature, the CMOS realization VDGA as depicted of in Figure $2[34,35]$ can be usually provides electronic tunability through its three separate transfer gain cells M1A-M9A, M1B-M9B, and M1C-M9C and their transconductances are $g_{m A}=g_{m}, g_{m B}$ and $\mathrm{g}_{\mathrm{mC}}$, respectively.

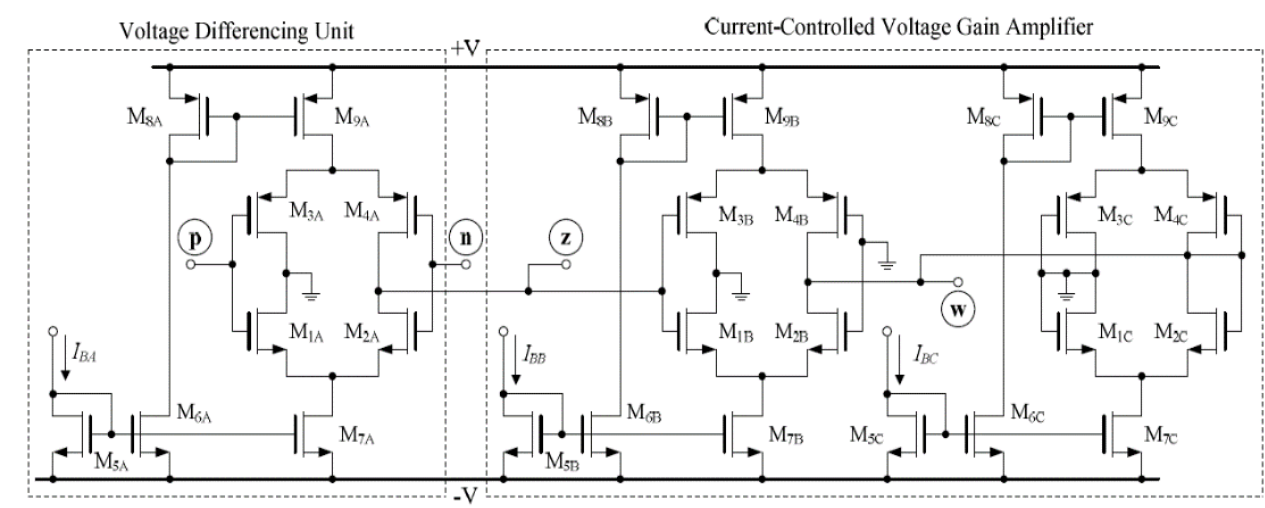

Figure 2. CMOS realization of the VDGA $[34,35]$ 
The proposed circuit of realization variable phase shift sinusoidal oscillator is shown in Figure 3. It enjoys with four floating outputs $\mathrm{V}_{\mathrm{o} 1}, \mathrm{~V}_{\mathrm{o} 2}, \mathrm{~V}_{\mathrm{o} 3}$ and $\mathrm{V}_{\mathrm{o} 4}$ where $\mathrm{V}_{\mathrm{o} 1}$ and $\mathrm{V}_{\mathrm{o} 3}$ have the same phase while the other two $\mathrm{V}_{\mathrm{o} 2}$ and $\mathrm{V}_{\mathrm{o} 4}$ have another same phase, the shift between their phases can be changed from $0^{\circ}-90^{\circ}$. The amplitude gain of the output circuit can be controlled separately by varying the transeconductances of the $\mathrm{B}$ and $\mathrm{C}$ celles as written in (2):

$$
\beta_{i}=\frac{g_{m B i}}{g_{m C i}}
$$

where $i=1,2,3$ and 4 for the $\mathrm{i}^{\text {th }}$ VDGA.

Hence Vw can be adjusted by means of $I B B$ and $I B C$ that showed in Figure 2.

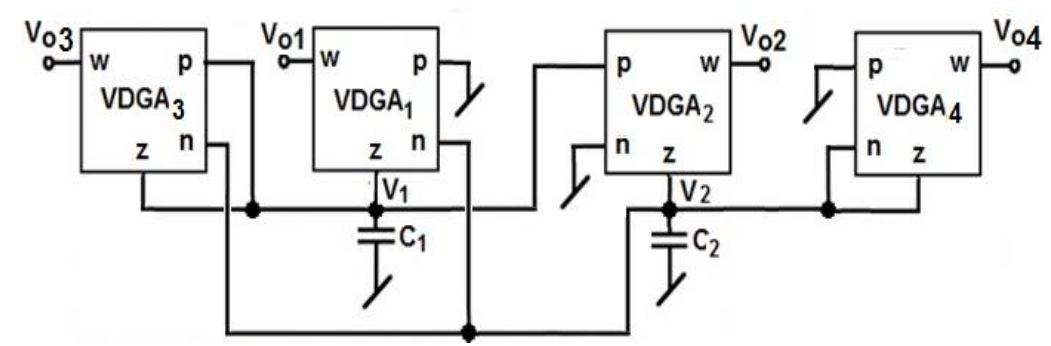

Figure 3. The proposed variable phase shift oscillator circuit.

Analysing the proposed circuit of Figure 3 reveals the following characteristic equation:

$$
s^{2} C^{2}+s C\left(g_{m 4}-g_{m 3}\right)+g_{m 3}\left(g_{m 2}-g_{m 4}\right)+g_{m 1} g_{m 2}
$$

where $\mathrm{C}=\mathrm{C}_{1}=\mathrm{C}_{2}$

The frequency of oscillation (FO), the condition of oscillation (CO) and the condition of phase shift angle can be obtained as:

$$
\begin{aligned}
& C O: g_{m 4} \leq g_{m 3} \\
& \text { FO: } \omega_{o}=2 \Pi f_{o}=\sqrt{\left[g_{m 3}\left(g_{m 2}-g_{m 4}\right)+g_{m 1} g_{m 2}\right] / C^{2}}
\end{aligned}
$$

The condition of the phase shift angle (PO) between $\mathrm{V}_{1}$ and $\mathrm{V}_{2}: \frac{V_{1}}{V_{2}}=\frac{1}{g_{m 2}}\left(g_{m 4}+s C_{2}\right)$

From the equations above, the phase shift can be controlled by changing the ratio of $\left(g_{\mathrm{m} 4} / \mathrm{g}_{\mathrm{m} 2}\right)$ then the desired angle can be obtained. The oscillation condition $(\mathrm{CO})$ can be adjusted by $\mathrm{g}_{\mathrm{m} 3}$ and the frequency condition (FO) controlled independently by $\mathrm{g}_{\mathrm{m} 1}$.

\section{NON IDEAL ANALYSIS}

In this section, the effect of non-idealities of the VDGA on the characteristic equation of the proposed oscillators has been stated; the VDGA can be specified by the following set of equations:

$$
I_{p}=I_{n}=0, I_{z}=\alpha g_{m}\left(V_{P}-V_{N}\right) \text { and } V_{w}=\beta V_{z}
$$

where $\alpha=1-\varepsilon$, and $|\varepsilon|<<1$ denotes the transconductance error of the VDGA.

Similarly, deriving the non-ideal characteristic equation of the proposed variable phase angle oscillator circuit of Figure 3 by taking the VDGA non-idealities yields:

$$
s^{2} C^{2}+s C\left(\alpha_{4} g_{m 4}-\alpha_{3} g_{m 3}\right)+\alpha_{3} g_{m 3}\left(\alpha_{2} g_{m 2}-\alpha_{4} g_{m 4}\right)+\alpha_{1} \alpha_{2} g_{m 1} g_{m 2}
$$

Therefore, modified of the oscillation frequency (FO), oscillation condition (CO) and phase shift angle condition are gotten as: 
$\mathrm{CO}: \alpha_{4} g_{m 4} \leq \alpha_{3} g_{m 3}$

FO: $\omega_{o}=2 \Pi f_{o}=\sqrt{\left[\alpha_{3} g_{m 3}\left(\alpha_{2} g_{m 2}-\alpha_{4} g_{m 4}\right)+\alpha_{1} \alpha_{2} g_{m 1} g_{m 2}\right] / C^{2}}$

The the condition of phase shift angle (PO): $\frac{V_{1}}{V_{2}}=\frac{1}{\alpha_{2} g_{m 2}}\left(\alpha_{4} g_{m 4}+{ }_{s} C_{2}\right)$

The new equations (8-10) with respect to non-ideal VDGA of the proposed circuit show that as a result of tracking error of the VDGA, the quantities of the CO, FO and PO are slightly changed, which can be compensated by $\mathrm{g}_{\mathrm{mi}}$, where $\mathrm{i}=1,2,3$ and 4 , of the VDGAs.

\section{INFLUENCE OF VDGA PARASITIC IMPEDANCE}

The influence of the parasitic elements of the VDGA on the characteristic equation of the proposed oscillators has been re-analyzed. The simplified non-ideal macro model of VDGA used for analysis is shown in Figure 4. Figure 4 shows the equivalent parasitic impedances existing at the terminals $\mathrm{p}, \mathrm{n}, \mathrm{z}$, and $\mathrm{w}$ of the nonideal VDGA as represented terminal conductance $G_{p}, G_{n}, G_{z}, G_{w}$ and capacitance $C_{p}, C_{n}, C_{z}$. Including these parasitic impedances, the complete structure of the nonideal circuit of the proposed oscillator is represented in Figure 5.

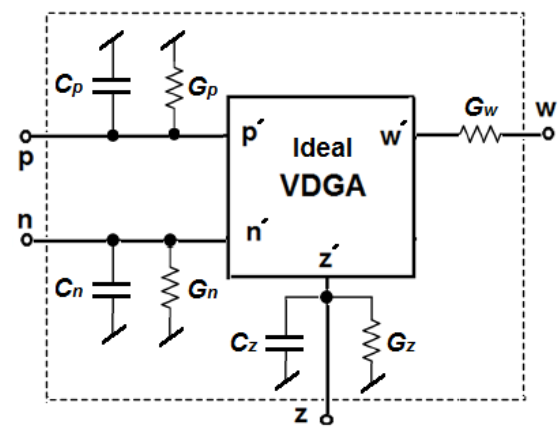

Figure 4. The simplified non-ideal macro model of VDGA

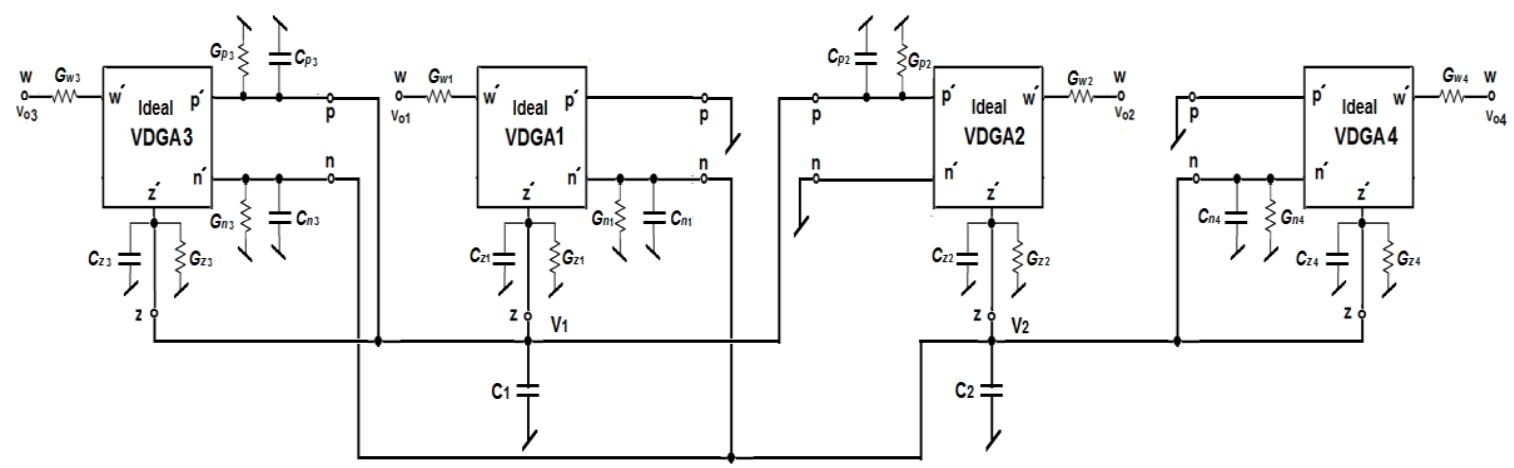

Figure 5. The nonideal circuit of the proposed oscillator

The non-ideal characteristic equation of the proposed variable phase shift oscillator circuit of Figure 5 is given by:

$$
\begin{gathered}
s^{2} C^{2}+s C_{T}\left(g_{m 4}-g_{m 3}+G_{t 1}+G_{t 2}\right)+g_{m 3}\left(g_{m 2}-g_{m 4}-G_{t 2}\right)+g_{m 1} g_{m 2} \\
+G_{t 1}\left(g_{m 4}+G_{t 2}\right)
\end{gathered}
$$

The FO, CO and the phase angle condition (PO) of the proposed variable sinusoidal oscillator circuit under non-ideal conditions are usually found as: 
$\mathrm{CO}: g_{m 4} \leq g_{m 3}-G_{t 1}-G_{t 2}$

FO: $\omega_{o}=2 \Pi f_{o}=\sqrt{\left[g_{m 3}\left(g_{m 2}-g_{m 4}-G_{t 2}\right)+g_{m 1} g_{m 2}+G_{t 1}\left(g_{m 4}+G_{t 2}\right)\right] / C_{T}^{2}}$

PO: $\frac{V_{1}}{V_{2}}=\frac{1}{g_{m 2}}\left(\left(g_{m 4}+G_{t 2}\right)+s C_{2}\right)$

where $C_{T}=C_{1}+C_{z 1}+C_{z 3}+C_{p 2}+C_{p 3}=C_{2}+C_{z 2}+C_{z 4}+C_{n 1}+C_{n 3}+C_{n 4}$,

$G_{t 1}=G_{z 1}+G_{z 3}+G_{p 2}+G_{p 3}$ and $G_{t 2}=G_{z 2}+G_{z 4}+G_{n 1}+G_{n 3}+G_{n 4}$

Equations (7-9) show the new CO, FO and PO that are slightly affected by the parasitic impedances. As seen in Figure 5 the parasitic capacitances are in parallel with external passive components $\left(\mathrm{C}_{1}\right.$ and $\left.\mathrm{C}_{2}\right)$, to eliminate these small diviation the external capacitance elements are chosen such that $C_{1} \gg C_{z 1}+C_{z 3}+C_{p 2}+C_{p 3}, C_{2} \gg C_{z 2}+C_{z 4}+C_{n 1}+C_{n 3}+C_{n 4}$, then the above equations have almost same as their ideal counterparts. To obtain a quantitative assessment of the values of errors achieved by the various parasitic elements of the VDGAs, it has been found that with $G_{z 1}=G_{z 2}=G_{z 3}=G_{z 4}=$ $0.5 \mu \mathrm{A} / \mathrm{V}, G_{p 1}=G_{p 2}=G_{p 3}=G_{p 4}=0.5 \mu \frac{A}{V}, G_{n 1}=G_{n 2}=G_{n 3}=G_{n 4}=0.5 \mu \frac{A}{V}, C_{z 1}=C_{Z 2}=C_{z 3}=C_{z 4}=$ $0.05 p F, C_{p 1}=C_{p 2}=C_{p 3}=C_{p 4}=C_{n 1}=C_{n 2}=C_{n 3}=C_{n 4}=0.05 p F$, and passive elements $C_{1}=C_{2}=10$ $p F$, the radians frequency ( $\left.\omega_{o}^{\prime}\right)$ of the non-ideal oscillator value is $26647015 \mathrm{rad} / \mathrm{sec}$ against its ideal value of $\omega_{\mathrm{o}}=27207553 \mathrm{rad} / \mathrm{sec}$, that produces the error to be around $2 \%$.

\section{SIMULATION RESULT}

One of the advantages of the proposed design, the variable phase shift oscillator angle can be changed from $0^{\circ}$ to $90^{\circ}$. To verify the performance of the oscillator phase shift angle change between $V_{1}$ and $\mathrm{V}_{2}$ of Figure 5, four angles have been selected $\left(30^{\circ}, 45^{\circ}, 60^{\circ}\right.$ and $\left.90^{\circ}\right)$ that cover approximately all the range of the angle change. To simulate and confirm the validity of the proposed sinusoidal oscillator circuit, the cadence PSPICE software has been used. Realizing the generator configuration of Figure 5 is carried out using the CMOS VDGA implementation as shown in Figure 2. PSPICE simulation based upon a CMOS VDGA was realized using $0.35 \mu \mathrm{m}$ technology, where the dimensions of the aspect ratio (W/L ) of the CMOS transistors are $\mathbf{M}_{1 \mathrm{j}}, \mathrm{M}_{2 \mathrm{j}}=10 / 1 \mu \mathrm{m}, \mathrm{M}_{3 \mathrm{j}}, \mathrm{M}_{4 \mathrm{j}}=10 / 0.75 \mu \mathrm{m}, \mathrm{M}_{5 \mathrm{j}}-\mathrm{M}_{7 \mathrm{j}}=15 / 0.4 \mu \mathrm{m}$ and $\mathrm{M}_{8 \mathrm{j}}$, $\mathrm{M}_{9 \mathrm{j}}=20 / 0.4$ where $j=A, B, C$ VDGA cells.

Performing the proposed circuit simulation with different angles $\left(30^{\circ}, 45^{\circ}, 60^{\circ}\right.$ and $\left.90^{\circ}\right)$, the $\mathrm{CMOS}$ VDGA was biased with DC power supply voltages $V_{D D}=+1.5 \mathrm{~V}, V_{S S}=-1.5 \mathrm{~V}, \mathrm{C} 1=\mathrm{C}_{2}=1 \mathrm{pF}$, and the voltage gain $(\beta)$ of the four VDGAs equal one $\left(I_{B B}=I_{B C}=130 \mu \mathrm{A}, \mathrm{g}_{\mathrm{mB}}=\mathrm{g}_{\mathrm{mC}}=315.3 \mu \mathrm{A} / \mathrm{V}\right)$. Table 1 shows the biased currents and their trransconductance of the circuit VDGAs, also the transconductance values achieved in the simulations along with the practical and theoretical output frequencies and total harmonic distortions (THD) for the new generator circuit are presented. SPICE frequency simulations of the generated voltage waveforms have been found a very good matching between simulation and theoretical values, and PSPICE THD simulations of the generated voltage waveforms were 2.29-3.32\%, thus, the results were reasonability values (less than $4.5 \%$ ).

Figure 6 (a-d) and Figure 7 (a-d) show the simulation of the transient and steady state voltage waveforms, respectively with phase shift angle $30^{\circ}, 45^{\circ}, 60^{\circ}$ and $90^{\circ}$ while Figure 8 (a-d) show frequency spectrum waveforms also with same with phase shift angle of these waveforms. The proposed generator design enjoys independently tuned voltage gain which any one of the floating outputs $\left(\mathrm{V}_{\mathrm{o} 1}, \mathrm{~V}_{\mathrm{o} 2}, \mathrm{~V}_{\mathrm{o} 3}\right.$ and $\left.\mathrm{V}_{\mathrm{o} 4}\right)$ can be controlled electronically by the transconductance of B or $\mathrm{C}$ cell showed in Figure 2, hence, the circuit has explicit voltage mode and a wide range of the controlled output gain. Figure 9 shows the equi-amplitude output voltage waveforms with different phase shift angles $\left(30^{\circ}, 45^{\circ}, 60^{\circ}\right.$ and $\left.90^{\circ}\right)$ and their Lissajous patterns. These simulations comfirm the selected phase angle.

Table 1. The values of the biased currents and their transconductances for the proposed oscillator

\begin{tabular}{|c|c|c|c|c|c|c|c|c|c|c|c|c|}
\hline \multirow{2}{*}{$\begin{array}{l}\text { Phase } \\
\text { shift }\end{array}$} & \multirow{2}{*}{$\begin{array}{l}\mathrm{I}_{\mathrm{BA} 1} \\
\mu \mathrm{A}\end{array}$} & \multirow{2}{*}{$\begin{array}{c}\mathrm{g}_{\mathrm{m} 1} \\
\mu \mathrm{A} / \mathrm{V}\end{array}$} & \multirow{2}{*}{$\begin{array}{l}\mathrm{I}_{\mathrm{BA} 2} \\
\mu \mathrm{A}\end{array}$} & \multirow{2}{*}{$\begin{array}{c}\mathrm{g}_{\mathrm{m} 2} \\
\mu \mathrm{A} / \mathrm{V}\end{array}$} & \multirow{2}{*}{$\begin{array}{l}\mathrm{I}_{\mathrm{BA} 3} \\
\mu \mathrm{A}\end{array}$} & \multirow{2}{*}{$\begin{array}{c}\mathrm{g}_{\mathrm{m} 3} \\
\mu \mathrm{A} / \mathrm{V}\end{array}$} & \multirow{2}{*}{$\begin{array}{l}\mathrm{I}_{\mathrm{BA} 4} \\
\mu \mathrm{A}\end{array}$} & \multirow{2}{*}{$\begin{array}{c}\mathrm{g}_{\mathrm{m} 4} \\
\mu \mathrm{A} / \mathrm{V}\end{array}$} & \multirow{2}{*}{$\begin{array}{c}\mathrm{F}_{\text {Simulation }} \\
\mathrm{MHz}\end{array}$} & \multirow{2}{*}{$\begin{array}{c}\mathrm{F}_{\text {Theoritical }} \\
\mathrm{MHz}\end{array}$} & \multicolumn{2}{|c|}{ THD \% } \\
\hline & & & & & & & & & & & $\mathrm{V}_{1}$ & $V_{2}$ \\
\hline $30^{\circ}$ & 60 & 236.3 & 25 & 159.5 & 100 & 293.5 & 90 & 280.5 & 25 & 24.840 & 2.34 & 3.32 \\
\hline $45^{\circ}$ & 51 & 220.2 & 51 & 220.2 & 70.7 & 253.5 & 51 & 220.2 & 35 & 35.063 & 2.29 & 2.96 \\
\hline $60^{\circ}$ & 190 & 400.1 & 41.2 & 202.5 & 27 & 166.3 & 79.6 & 262.5 & 43 & 42.442 & 2.35 & 2.35 \\
\hline $90^{\circ}$ & 21.9 & 150.5 & 35 & 186.3 & 3.7 & 64.3 & 0.06 & 0.658 & 31 & 31.837 & 3.10 & 3.17 \\
\hline
\end{tabular}




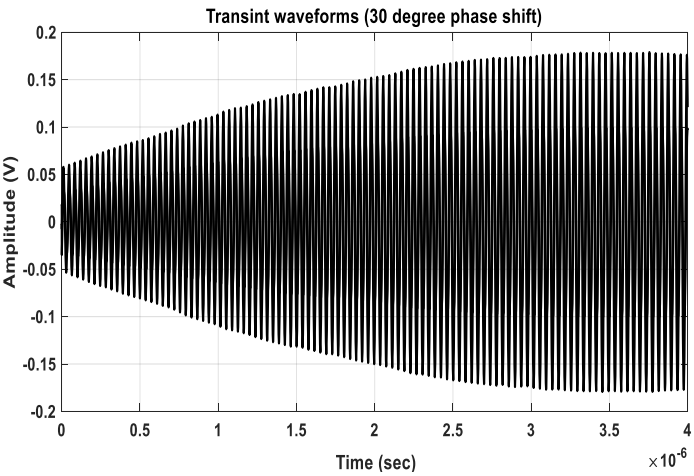

(a)

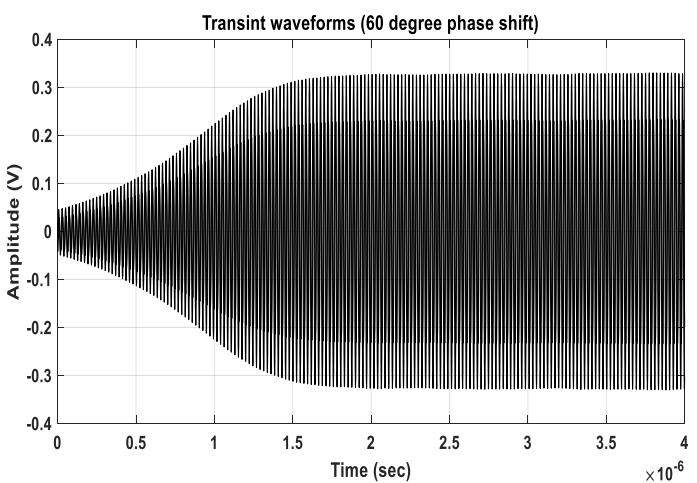

(c)

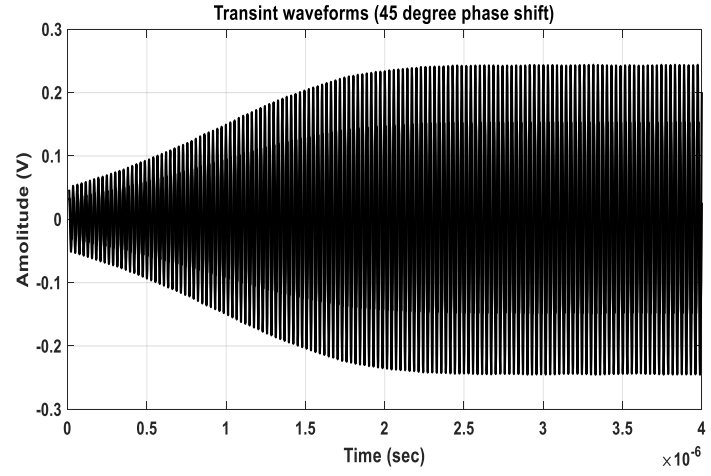

(b)

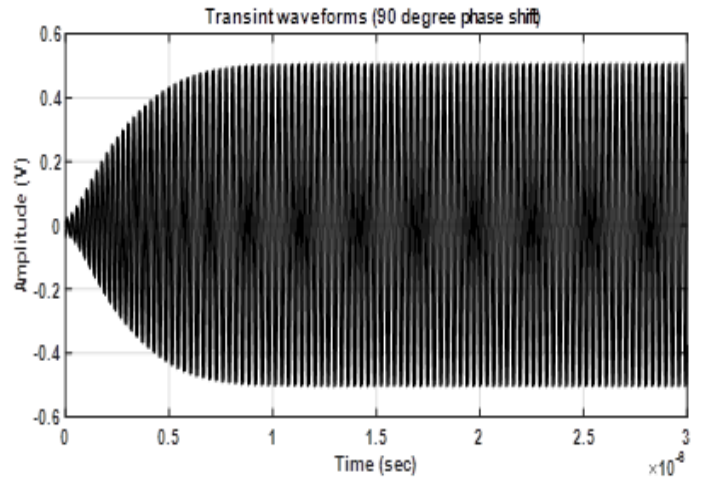

(d)

Figure 6. Transient voltage waveforms with phase shift (a) $30^{\circ}$ (b) $45^{\circ}$ (c) $60^{\circ}$ (d) $90^{\circ}$

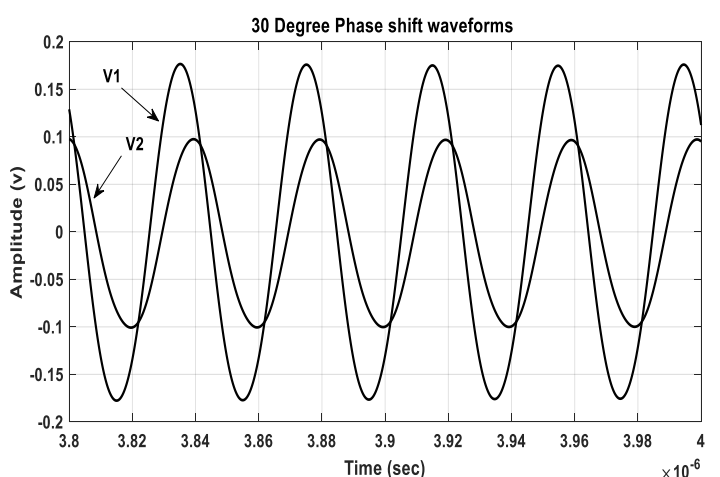

(a)

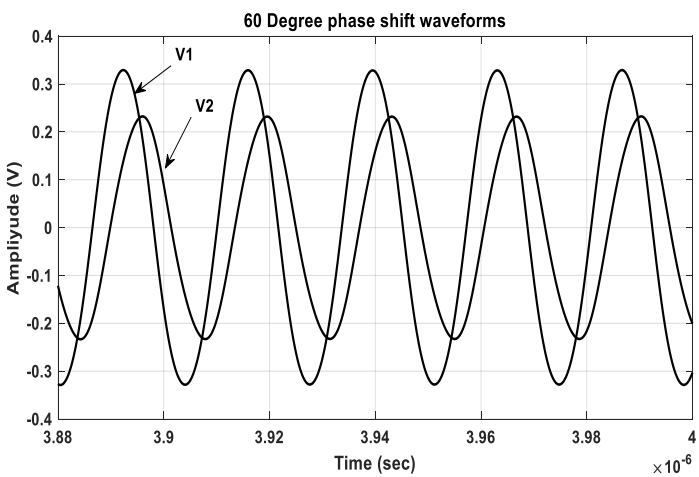

(c)

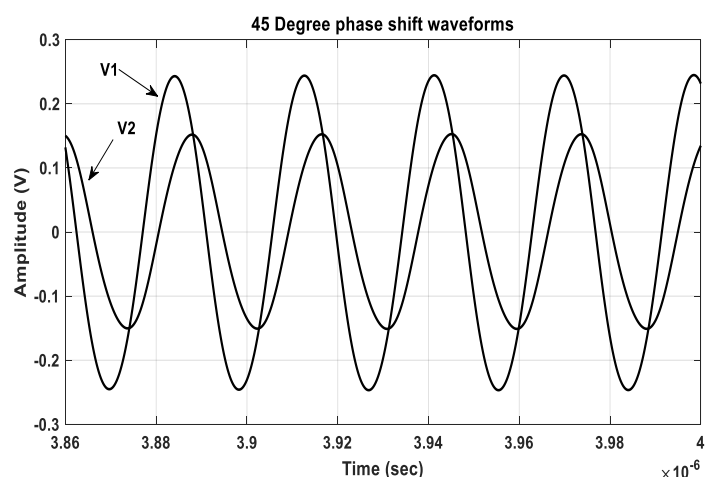

(b)

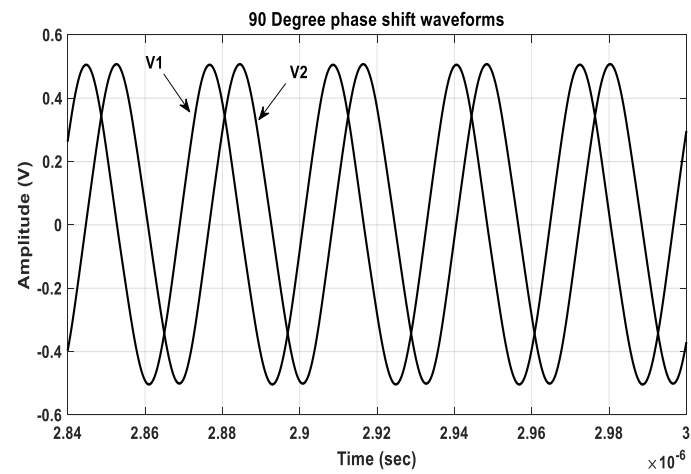

(d)

Figure 7. Steady state voltage waveforms with phase shift (a) $30^{\circ}$ (b) $45^{\circ}$ (c) $60^{\circ}$ (d) $90^{\circ}$ 


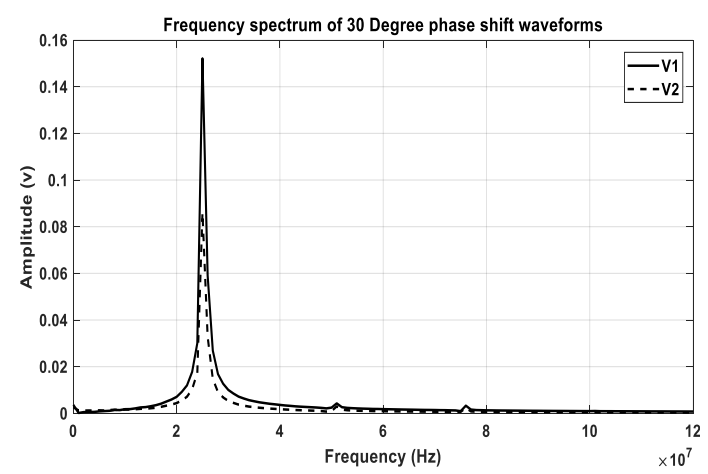

(a)

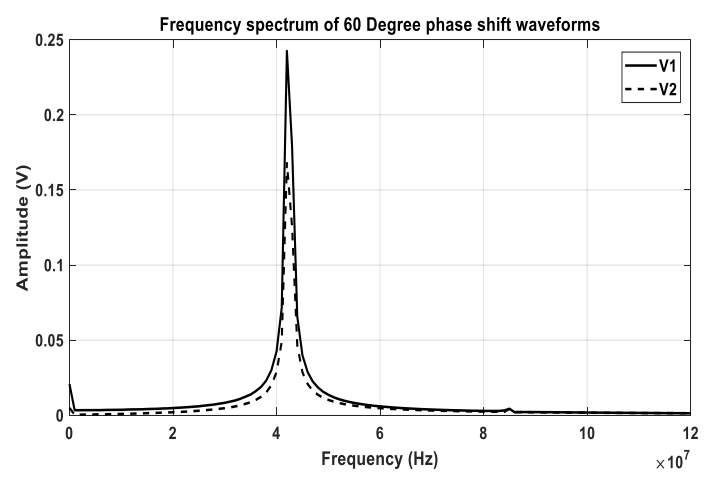

(c)

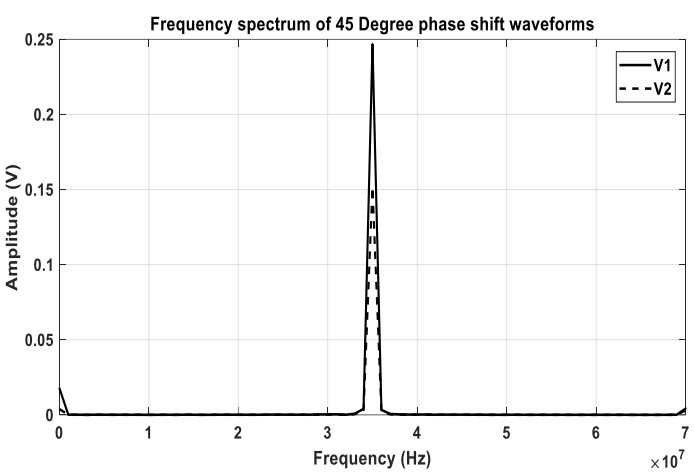

(b)

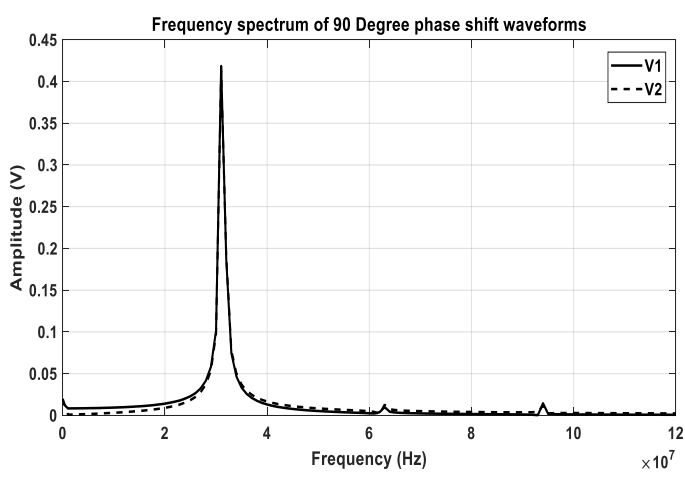

(d)

Figure 8 . Frequency spectrum with phase shift (a) $30^{\circ}$ (b) $45^{\circ}$ (c) $60^{\circ}$ (d) $90^{\circ}$
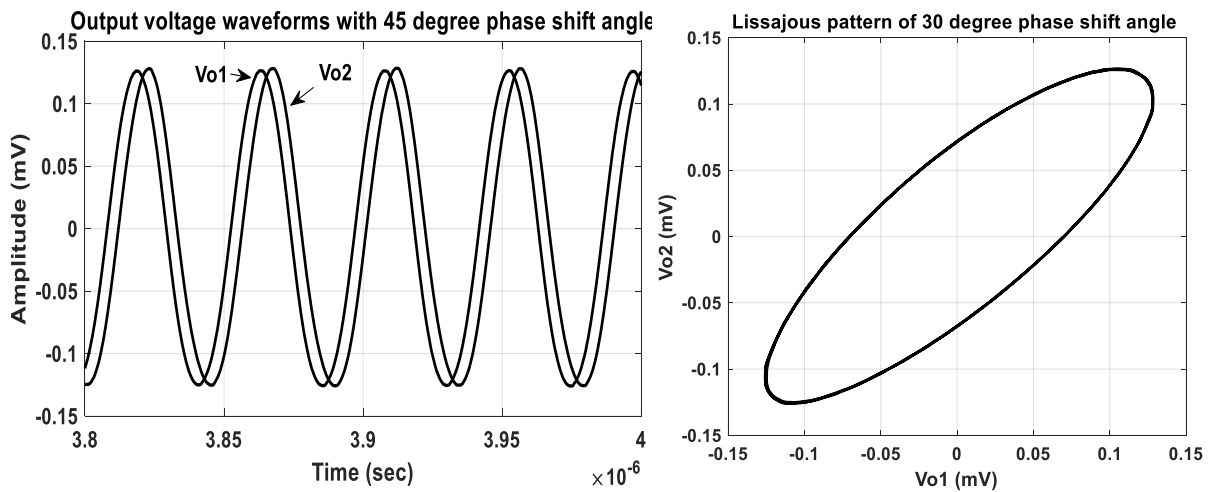

(a)
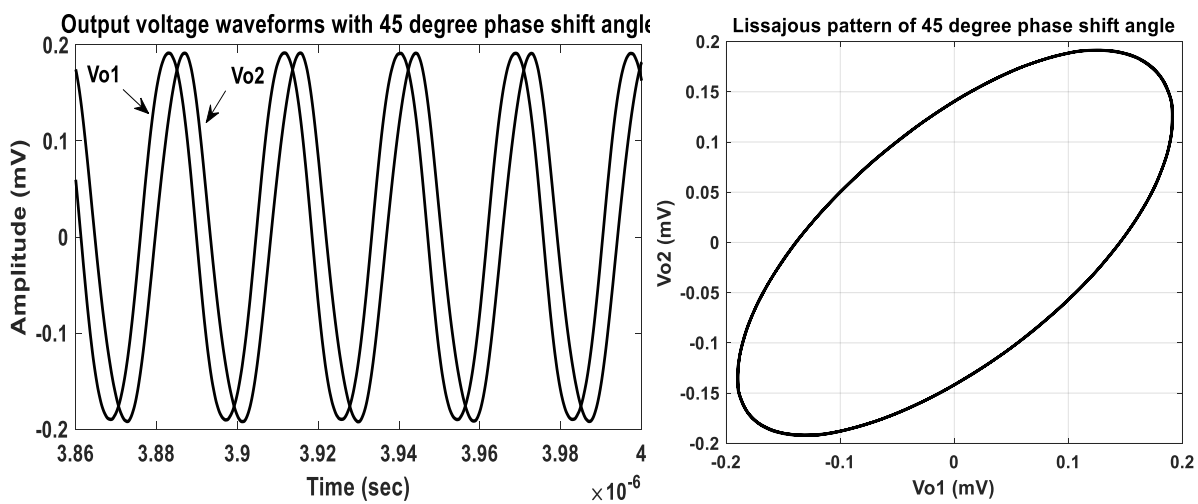

(b)

Figure 9. Equi-amplitude output voltage waveforms with different phase angles and their Lissajous patterns 

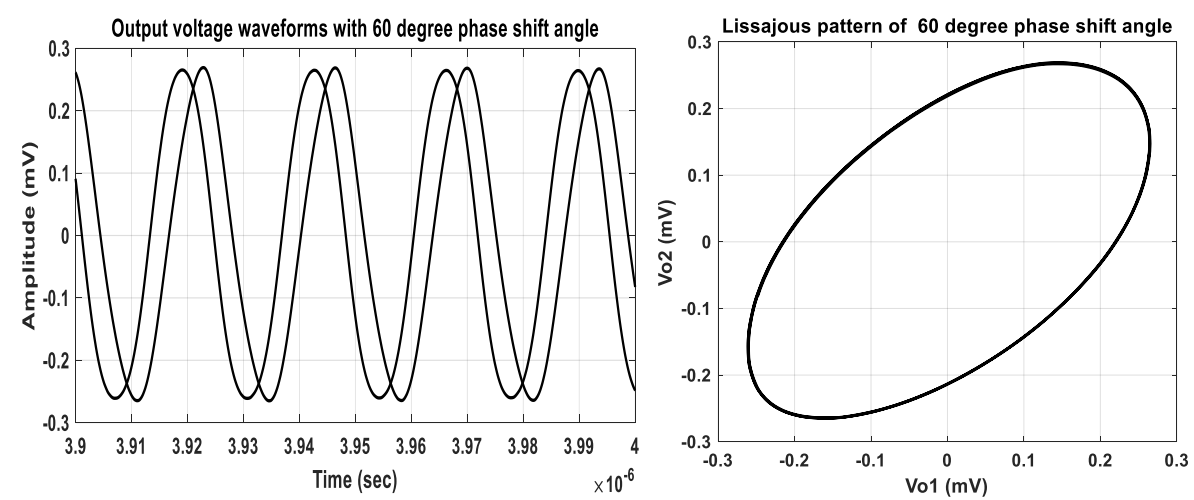

(c)
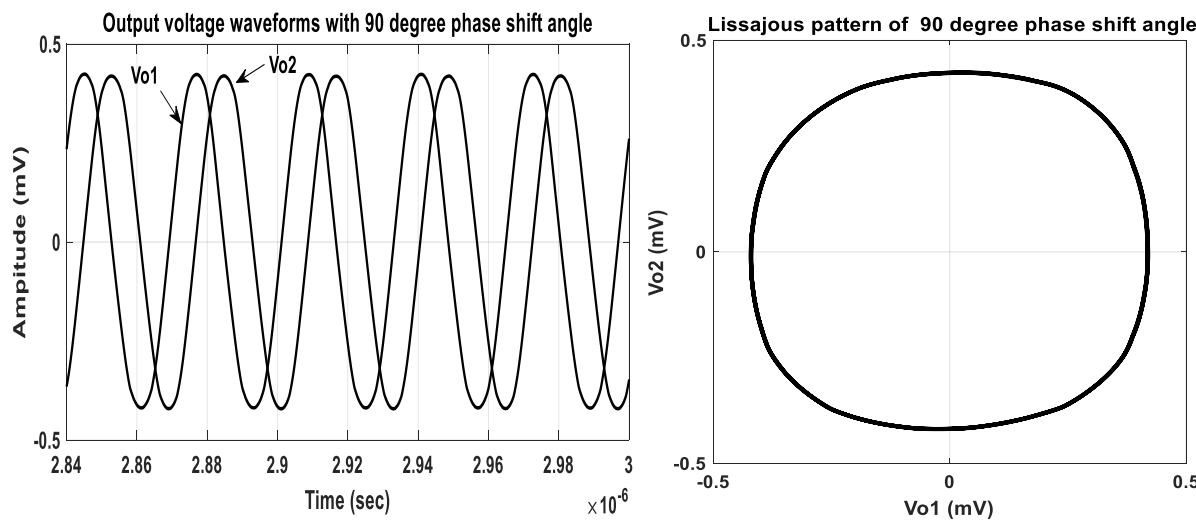

(d)

Figure 9. Equi-amplitude output voltage waveforms with different phase angles and their Lissajous patterns

\section{COMPARISON WITH OTHER WORKS}

There are many oscillator circuits which include; out of phase by $90^{\circ}$ called quadrature oscillator [8-15], out of phase by $45^{\circ}$ [16-19], out of phase by $120^{\circ}$ [20 (circuit of Figure 2 therein)-22] or hybrid phase angles [20 (circuit of Figure 4 therein)] or generate n number of signals equally spaced in phase which require $n$ units of active and passive devices [22, 23]. All these generators are specified with fixed phase shift angles like the phase shifter. While the proposed circuit has the characteristics of variable phase angle, variable output amplitude and reasonable values of THD, as well as has the simplicity. By simple modification, it can also generate variable phase shift by $90^{\circ}$ t0 $180^{\circ}$ by connecting another VAGA at point 2 in Figure 3 (ground terminal $n$ and connect terminals $\mathrm{p}$ and $\mathrm{z}$ to point 2 ).

\section{CONCLUSION}

There is not finding variable phase shift sinusoidal oscillator in the open literature. This paper introduces a novel interesting type of variable phase shift oscillator. Also introduces a new concept the condition of the phase angle of the oscillation (PO) which presents the phase shift condition of the desired angle. The new proposed oscillator configuration, that uses four voltage differencing gain amplifier (VDGA) and two grounded capacitors, can generate two sinusoidal signals. It has four floating outputs where every two outputs have the same phase with explicit voltage mode output. The proposed circuit offers (i) phase shift change out of phase by 0 to 90 degree (ii) the gain of the floating outputs can be controlled independently for a wide rang (iii) its PO can be tuned electronically (iv) electronic controllability of CO and independent control of FO. SPICE frequency simulations of the generated voltage waveforms have been found a very good matching between simulation and theoretical values, and PSPICE THD simulations of the generated voltage waveforms were 2.29-3.32 \%, thus, the results were reasonability values. The non-ideal analysis of the proposed circuit produces the error to be around $2 \%$ which represent acceptable value and simulation results and confirmed the theoretical analysis. The performance based VDGAs of the proposed configuration has been simulated using PSPICE program with CMOS $0.35 \mu \mathrm{m}$ parameters. 


\section{REFERENCES}

[1] R. Senani, "New types of sine wave oscillators," IEEE Trans. on Instrumentation and Measurement, vol. 34, no. 3, pp. 461-463, 1985.

[2] R. Senani and D. R. Bhaskar, "Single-op-amp sinusoidal oscillators suitable for generation of very low frequencies," IEEE Trans. on Instrumentation and Measurement, vol. 40, no. 4, pp. 777-779, 1991.

[3] J. Dunlop and D. G. Smith, "Telecommunications Engineering," (3 ${ }^{\text {rd }}$ ed.). CRC Press, 1994.

[4] W. Tomasi, "Electronic Communications System," New Jersey; Prentice- Hall Inc., 1998.

[5] D. R. Bhaskar and R. Senani, "New CFOA-based single-element-controlled sinusoidal oscillators," IEEE Transactions on Instrumentation and Measurement, vol. 55, no. 6, pp. 2014-2021, 2006.

[6] D. R. Bhaskar, et al., "New SRCO with explicit current-mode output using two CCs and grounded capacitors," Turk. Journal Eng. \& Comp. Sci, vol. 19, no. 2, 2011.

[7] M. M. Elsherbini, M. F. Elkordy and A. M. Gomaa, "Design and Simulation for UHF Oscillator using SAWR with Different Schematics," Indonesian Journal of Electrical Engineering and Computer Science, vol. 1, no. 2, pp. 294- 299, January 2016.

[8] I. A. Khan, et al., "Tunable OTA based multiphase sinusoidal oscillators," International journal of Electronics, vol. 72, pp. 443-450, 1992.

[9] D. S. Wu, et al., "Multiphase sinusoidal oscillator using second generation current conveyors," Int. J. Electronics, vol. 78, no. 4, pp. 645-651, 1995.

[10] K. Klahan, et al., "Realization of multiphase sinusoidal oscillator using CDBAs," in Circ. Sys., Proc. of the IEEE Asia-Pacific Conf., pp. 725-728, 2004.

[11] P. Mongkolwai, et al., "CFOA-based single resistance controlled quadrature oscillator," in Control and Information Technology, Proceedings of the International Conference on Instrumentation, pp. 1147-1150, 2008.

[12] W. Tangsrirat, and W. Tanjaroen, "Current-mode multiphase sinusoidal oscillator using current differencing transconductance amplifiers," Cir., Sys., Signal Process, vol. 21, pp. 81-93, 2008.

[13] W. Tangsrirat, et al., "Current-mode multiphase sinusoidal oscillator using CDTA-based allpass sections," Int. J. Electron. Commu. (AEU), vol. 63, pp. 616-622, 2009.

[14] W. Jaikla, et al., "High output-impedance current-mode multiphase sinusoidal oscillator based on CDTA-allpass filters," Int. Journal of Electronics, vol. 97, no. 7, pp. 811-826, 2010.

[15] K. K. Abdalla, et al., "Configuration for Realizing a Current-Mode Universal Filter and Dual-Mode Quadrature SRCO," IET Circuits, Devices and Systems, vol, 6, no. 3, pp. 159-167, 2012.

[16] N. Herencsar, et al., "New compact VM four-phase oscillator employing only single Z-copy VDTA and all grounded passive elements," Elektronika IR Electrotechinka, vol. 19, no. 10, pp. 87-90, 2013.

[17] R. Sotner, et al., "Second-order simple multiphase oscillator using Z-copy controlled-gain voltage differencing current conveyor", Elektronika IR Electrotechinka, vol. 20, no. 9, pp. 13-18, 2014.

[18] S. Maheshwari, "Sinusoidal generator with $\pi / 4$ shifted four/eight voltage outputs employing four grounded components and two/six active elements," Active and passive electronic components, 2014, 7 pages, 2014.

[19] K. K. Abdalla, "New Two Simple Sinusoidal Generators with Four $45^{\circ}$ Phase Shifted Voltage Outputs Using Single FDCCII and Grounded Components," International Journal of Electrical and Computer Engineering (IJECE), vol. 8, no.6, pp. 5080-5088, 2018.

[20] M. M. Heima and H. H. Mohamed "Active-R Oscillators Based On Cascaded First-Order Building Blocks (Part I)," The Online Journal on Electronics and Electrical Engineering (OJEEE), vol. 1, no. 2, pp. 94-98, 2009

[21] F. Llopis, J González and M Jakas, "A low-voltage three-phase AC generator built from analogue blocks," WSEAS Transactions on Circuits and Systems, vol. 13, pp. 262-265, 2014.

[22] S. Siripongdee, et al., "Electronically Controllable Current-Mode Multiphase Sinusoidal Oscillator for Biomedical Tissue Measurement Systems," International Journal of Bioscience, Biochemistry and Bioinformatics, vol. 4, no. 1, pp. 57-59, 2014.

[23] D. S. Wu, S. I. Liu, Y. S. Hwang and Y .P. Wu, "Multiphase sinusoidal oscillator using second generation current conveyors," International Journal Electronics, vol. 78, no. 4, pp. 645-651, 1995.

[24] D. Biolek, R. Senani, V. Biolkova and Z. Kolka, "Active elements for analog signal processing: Classification, review, and new proposals," Radioengineering, vol. 17, no. 3, pp. 15-32, 2008.

[25] K. K. Abdalla, et al.," A review of the evolution of current-mode circuits and techniques and various modern analog circuit building blocks," Nature and Science, vol. 10, no. 10, pp. 1-13, 2012.

[26] D. R. Bhaskar, et al., "Electronically-Controlled Current-mode second order Sinusoidal Oscillators Using MO-OTAs and Grounded Capacitors," Circuits and Systems, vol. 2, no. 1, pp. 65-73, 2011.

[27] F. Syifaul, E. Hakkun and Suwasono, "Design and Fabrication of LC-Oscillator Tool Kits Based Op-Amp for Engineering Education Purpose," Indonesian Journal of Electrical Engineering and Computer Science, vol. 1, no. 1, pp. 88- 100, January 2016.

[28] K. K. Abdalla, "New High-Input Impedance MISO-Type Universal Biquad Filter Employing CFOAs," Journal of Telecommunications, vol. 27, no. 2, pp.28-32, 2014.

[29] N. Herencsar, et al., "New compact VM four-phase oscillator employing only single Z-copy VDTA and all grounded passive elements," Elektronika IR Electrotechinka, vol. 19, no. 10, pp. 87-90, 2013.

[30] R. Senani, et al., "A State Variable Method for the Realization of Universal Current-Mode Biquads," Circuits and Systems, vol. 2, pp. 65-73, 2011.

[31] K. K. Abdalla, "Universal Current-Mode Biquad Employing Dual Output Current Conveyors and MO-CCCA with Grounded Passive Elements," Circuits and Systems, vol. 4, pp. 83-88, 2013. 
[32] R. Sotner, et al., "Second-order simple multiphase oscillator using Z-copy controlled-gain voltage differencing current conveyor," Elektronika IR Electrotechinka, vol. 20, no. 9, pp. 13-18, 2014.

[33] K. K. Abdalla, "Current-Mode MISO-Type Universal Biquad Employing Single FDCCII and Grounded Passive Components," European Journal of Scientific Research, vol. 128, no 3, pp. 283-290, 2015.

[34] O. Channumsin, W. Tangsrirat, "Compact electronically tunable quadrature oscillator using single voltage differencing gain ampli_er (VDGA) and all grounded passive elements," Turkish Journal of Electrical Engineering \& Computer Sciences, vol. 25, pp. 2686-2695, 2017.

[35] J. Satansup, W. Tangsrirat, "CMOS realization of voltage differencing gain amplifier (VDGA) and its application to biquad filter," Indian J. Eng. Mater. Sci., vol. 20, no. 6, pp. 457-464, 2013. 